RESEÑAS

$324-327$

\title{
Giorgio Agamben (2020). El Reino y el Jardín. Madrid: Sexto Piso. 132 pp.
}

El ensayo de Giorgio Agamben El Reino y el Jardín nos ofrece un riguroso esfuerzo por elucidar el paradigma de la felicidad en el mundo cristológico occidental, dicho paradigma se escinde a partir de dos momentos: el Paraíso y el Reino. En este sentido, Walter Benjamín nos dice que cualquier intento de situar un fenómeno dialécticamente afuera de la continuidad histórica lineal, termina por escindirlo en prehistoria y posthistoria, ambos momentos inaccesibles para el hombre. El presente se escinde a partir de esos dos momentos inaccesibles, que representan una promesa que está por venir.

Así, la idea teológica de la felicidad que está presente en la conciencia del hombre occidental, y que está al margen del pensamiento occidental, forma parte de un orden secular. Carl Schmitt sostiene que los conceptos de la moderna teoría del Estado son conceptos secularizados, entonces la promesa de la felicidad está capturada en un dispositivo teológico-político. La promesa de felicidad recorre la conciencia del mundo antiguo y moderno y depende de la idea del Paraíso y Reino. Dicha problemática alcanza al mismo Marx, según Benjamín, la idea de una sociedad sin clases es una secularización del Reino mesiánico.

El primer capítulo hace referencia al tríptico El jardín de las delicias de Jheronimus Bosch, el que intenta ser restituido a la coyuntura teológica en la que nació, los hermanos del Libre Espíritu consideran que el perfeccionamiento del espíritu coincide con la llegada del Reino, en esta narración existe una posibilidad de restitución, pero esta es lanzada hacia el futuro. "Se ha podido afirmar que no es el paraíso sino su pérdida lo que constituye el mitologema original de la cultura occidental"1. La marca originaria que se inscribe en el hombre occidental es una pérdida referida a un momento inmemorial que está tachado desde el inicio. El origen es una pérdida, pero también un extravío.

El segundo capítulo intitulado La naturaleza del pecado se concentra en una discusión acerca de la tesis agustiniana del pecado original. Precisamente, la doctrina agustiniana del pecado original está atravesada por razones teológicas y eclesiásticas, cuyo contenido muchas veces se articula de forma indiscernible, "Agustín comprende que debe de incluir en el pecado la naturaleza humana [...]. Y la razón que él aduce ante todo es que si la naturaleza humana puede ser justa, entonces Cristo murió en vano" (p. 32). Según lo anterior, la presencia del pecado en el origen de la naturaleza humana, muestra irrevocablemente la necesidad de una economía de salvación representada en los sacramentos, ya que estos sirven para borrar la marca que se encuentra en el origen.

Así, la discusión de la doctrina del pecado original encuentra sentido en la explicación pelagiana de este asunto. Pelagio niega que exista una mácula original en los hombres. Si bien Agustín parece sostener que el pecado es un acto y no una sustancia,

\footnotetext{
${ }^{1}$ Agamben, Giorgio (2020) El Reino y el Jardín, Madrid: Sexto piso (p. 21)
} 
debemos preguntarnos: ¡cómo pudo transmitirse a todos los hombres? Lo anterior abre una ambivalencia, pues si el pecado responde a la voluntad, entonces parece ser que los hombres podrían elegir no pecar. Por ello, Pelagio niega que pueda existir una distinción entre gracia y naturaleza, más bien ambas se corresponden, es decir, la gracia participa íntimamente en la naturaleza del hombre y le fue dada en el momento de su creación. No obstante, Agustín sostiene que Pelagio confunde naturaleza y gracia, pues si existe dentro de la naturaleza humana la posibilidad de no pecar, la gracia se convierte en algo superfluo. Agustín arguye en De natura et Gratia que la gracia es una medicina para la naturaleza humana, que ha sido corrompida por el pecado original ${ }^{2}$. La idea del pecado original en Agustín parece condenar irrevocablemente al hombre a una existencia afuera del paraíso. "Agustín se da cuenta de que, una vez interpretada literalmente, la narración del Génesis [...], hace del paraíso un pasado por siempre perdido"3. Precisamente, esta restitución de la naturaleza humana nunca será íntegra, pues el pecado original no puede ser cancelado, lo que deja al paraíso terrenal vacío. Del mismo modo, Tomás en $L a$ Summa Theologiae representa al Jardín del Edén como un lugar de residencia vacío y que ha sido creado inútilmente por Dios.

El tercer capítulo recupera los argumentos de Escoto Erígena referentes a la naturaleza humana. Supone que la creación puede ser entendida en dos momentos: la primera creación fue espiritual e inmortal, después una segunda creación se añade, en la que se agrega un cuerpo mortal y corruptible, es un recubrimiento inconstante y corruptible. "Dios, - dice Erígena- antes de que el hombre pecase, creó en el hombre y, al mismo tiempo que al hombre, las consecuencias del pecado" (p.63). El cuerpo corruptible no sería consecuencia del pecado, sino que participa de la naturaleza del hombre al igual que la gracia.

Así pues, una estrategia recurrente en los textos de Erígena es presentar las objeciones a sus propios argumentos. Erígena piensa que en la Ciudad de Dios Agustín utiliza el verbo en sentido incoativo, "el hombre vivía (vivebat) en el paraíso". El uso del incoativo hace suponer que la presencia del hombre en el paraíso nunca ocurrió, es decir, nunca pudo habitar en el paraíso. Erígena -siguiendo a Ambrosio- considera que el paraíso podría ser entendido como una imagen alegórica de la naturaleza humana, lo que implicaría que el hombre ha estado afuera del paraíso desde el comienzo.

Si el Jardín no es más que la naturaleza humana misma, entonces el hombre nunca entró en su naturaleza o siempre estuvo fuera de ella. Que el hombre nunca haya entrado en el paraíso, que lo que las Escrituras narran del pecado y de la caída se deba entender como ocurrido fuera del paraíso, significa que el pecado ocurrió fuera de la naturaleza humana, que ella nunca fue contaminada (p. 63).

\footnotetext{
${ }^{2}$ Hipona, Agustín (2007) Obras completas IX Escritos antipelagianos y Tratados sobre la gracia, Madrid: BAC.

${ }^{3}$ Agamben, Giorgio (2020) El Reino y el Jardín, Madrid: Sexto piso (p. 49).
} 
Esta idea de Erígena nos hace pensar que el mal radica en el abuso de los bienes contenidos en la naturaleza humana, la naturaleza humana (paraíso) es aquel sitio donde el hombre debe regresar. Según lo anterior, la caída no existió ya que el pecado ocurrió afuera de la naturaleza humana. El paraíso está intacto y ha permanecido inhabitado desde el origen. En términos de Erígena, el hombre nunca contaminó el paraíso y puede acceder a él.

El cuarto capítulo establece la concepción de Dante sobre el paraíso. El jardín del que habla Dante es un lugar en la tierra situado en la cima de un monte en el hemisferio meridional. El paraíso dantesco no está deshabitado, en él hay dos ríos, Eunoe y Leteo. En el Leteo se anula la memoria del pecado, aquellos que se sumergen en sus aguas sufren olvido. Evidentemente, la versión del paraíso dantesco es contraria a la que se encuentra en el Génesis, pues el Leteo indica la previsión del pecado. Además, el paraíso está habitado por una mujer que canta y danza, Matelda (Purgatorio, XVIII). "Para Dante, el paraíso terrenal, la figura de la beatitud terrena, era también el lugar de la justicia original de la naturaleza humana" (p. 78). La floresta espesa y viva y aquella áspera y dura, son el mismo lugar en el que se extravía el poeta, y donde se reencuentra. La espesa y viva floresta es una insinuación de la posible salvación del hombre. El paraíso es el lugar donde se expresa la "beatitud de esta vida", donde Matelda se encuentra cantando, recogiendo florecillas y donde los hombres pueden morar, es la posible beatitud del presente.

Posteriormente, el quinto capítulo establece una discusión entre los conceptos de naturaleza y gracia. Pietro Lombardo considera que el hombre había sido creado afuera del Jardín y solo en un segundo momento se le permitió morar ahí. Así, según esta concepción, Adán recibió los dones naturales y en un segundo momento recibió la gracia. Los gratuita y la pura naturalia tenían una relación estrecha con la naturaleza humana, solamente después del pecado la gracia cesó de existir en la naturaleza humana. Pura naturalia es el sedimento después del pecado. "Adán y Eva antes del pecado no se daban cuenta de su desnudez, no por inocencia, sino porque estaba recubierta de un vestido de gracia" (p. 100). Entonces, la naturaleza humana es definida desde la ausencia, precisamente lo que define a la naturaleza humana es la ausencia de gracia.

Efectivamente, el pecado es el operador que divide la pura naturalia y los gratuita. El pecado es determinante en la escisión del dispositivo, pues impide que coincida la naturaleza y gracia. "La incorruptibilidad y la inmortalidad de los miembros paradisíacos de Adán antes del pecado no provenían de la naturaleza, sino de la gracia" (p. 105). Por ello, Agustín insiste en el carácter animal de la naturaleza humana, menciona que el hombre fue creado como alma viviente y no en un espíritu vivificante.

Pero, en Erígena podemos encontrar una refutación de la doctrina que considera al hombre como un ser escindido, ya que Dios ha creado al hombre en el género animal porque ha querido que en él esté toda la naturaleza, "el hombre está en todos los animales y todos los animales están en el hombre" (p.110). El pecado es un acto de voluntad, no es constitutivo de la naturaleza, lo que abre la posibilidad de pensar que la entrada al jardín es 
posible. Dante también supone que el hombre puede entrar al Jardín, lugar donde se encuentra con la inocencia y justicia original ${ }^{4}$.

Finalmente, el sexto capítulo examina el vínculo entre Reino y Jardín en la tradición cristiana. "Y en Apocalipsis, 2, 7, el Espíritu anuncia que al victorioso [...] le haré comer del árbol de la vida que está en el paraíso de Dios" (p. 118). Agamben menciona que también en el judaísmo tardío se presenta esta idea del Reino terrenal. El jardín y el Reino parecen ser el mismo lugar. Sin embargo, en la Ciudad de Dios se puede apreciar cómo Agustín identifica al Reino con el tiempo de la Iglesia, es decir, Reino hace referencia a los asuntos terrenales de la Iglesia, es una preparación para el Reino celestial. El Reino queda vacío de todo contenido político y este se identifica solamente con los acontecimientos terrenales, la idea de Reino se proyecta hacia el futuro y se convierte en una promesa para los justos.

Esta temporalidad también se encuentra en el término paulino, parousia. Parousia indica la presencia y advenimiento de Cristo al final de los tiempos. Pablo comprende el tiempo mesiánico en dos momentos: la resurrección y la segunda venida de Cristo. El tiempo mesiánico se convierte en kairos y chronos. "Lo mismo puede decirse del Reino: está presente aquí y ahora, pero está, al mismo tiempo, siempre en el acto de venir, siempre ad-veniente" (p. 130). El Reino se convierte en una promesa diferida al futuro.

El ensayo de Giorgio Agamben participa de una reconstrucción genealógica del paradigma teológico de Occidente. Su lectura política de Dante intenta desarticular la escisión entre prehistoria y posthistoria, pues el Jardín y el Reino forman parte de la experiencia presente y pueden ser accesibles al hombre a partir de la "beatitud de esta vida", tal como lo expresó Dante.

https://doi.org/10.32735/S0718-2201202100052901

Luis Alberto Jiménez

Universidad Autónoma Metropolitana-Xochimilco (México)

mluisalberto@gmail.com

\footnotetext{
${ }^{4}$ Alighieri, Dante (2014) La divina comedia, Madrid: Cátedra.
} 